\title{
Modelling transfer to animals accounting for trans-generational factors
}

\author{
J.E. Brown ${ }^{1}$, A. Hosseini ${ }^{1}$ and C. Seymour ${ }^{2}$ \\ ${ }^{1}$ Norwegian Radiation Protection Authority, P.O. Box 55, N-1332 Østeras, Norway \\ ${ }^{2}$ McMaster University, Canada, Hamilton, Ontario L8S4L8, Canada
}

\begin{abstract}
The FASTer-lite model is multi-compartmental model that can be used to simulate transfer through a simple terrestrial food-chain. The model uses allometric relationships to describe dietary intake rates and radionuclide biological half-lives; the latter were mostly derived from published literature. This type of conventional modelling, for simulating the transfer of radionuclides to representative animals such as birds, results in the observation that activity concentrations associated with ecological compartments approach an equilibrium after a certain time interval. Whilst this approach has validity, however, it is not biologically plausible as it ignores reproduction. In this study we calculate how activity concentrations may vary if transfer to eggs and subsequent growth dilution occurring within juvenile birds is accounted for.
\end{abstract}

\section{INTRODUCTION}

FASTer-lite is a multi-compartmental model that can be used to simulate transfer through a terrestrial ecosystem. It was originally set up to consider a simple food-chain consisting of vegetation-herbivorecarnivore in part to provide transfer parameters for organism-radionuclide combinations for which data were lacking in the process of developing a system to assess impacts of radiation on the environment [1].

The original configuration of the model was simplified due to fundamental concerns involving the conceptualization of the system which required, but did not explicitly include, population-related parameters. This simplified model was thereafter used to make predictions of activity concentrations in wild animals in terrestrial environment and appears to yield reasonable results in the sense that for most radionuclides and animals where predictions were made, results were not substantially different from those predicted using more conventional concentration ratio based approaches [2]. The model is represented in the form of an interaction matrix as shown in Figure 1.

Transfer from soil to a given dietary component is modelled using a simple concentration ratio approach (Equation 1) :

$$
\mathrm{C}_{\mathrm{r}, \mathrm{i}}=\mathrm{CR}_{\mathrm{r}, \mathrm{i}} \cdot \mathrm{C}_{\mathrm{r}, \text { topsoil }}
$$

Where :

$\mathrm{C}_{\mathrm{r}, \mathrm{i}}$ is the activity concentration of radionuclide " $\mathrm{r}$ " in dietary component "i" $\left[\mathrm{Bq} \mathrm{kg}^{-1}\right.$, f.w.]

$\mathrm{CR}$ is the concentration ratio of radionuclide " $\mathrm{r}$ " from soil to dietary component "i" [relative units] $\mathrm{C}_{\mathrm{r}, \text { topsoil }}$ is the activity concentration of radionuclide " $\mathrm{r}$ " in the topsoil [ $\mathrm{Bq} \mathrm{kg}^{-1}$, d.w.]

The $2^{\text {nd }}$ food-chain compartment has been parameterised specifically in terms related to ingestion, depuration (i.e. effective loss) rates and assimilation efficiencies. Hence, the change in activity concentration with time $\left(\mathrm{Bq} / \mathrm{kg} \mathrm{d}^{-1}\right)$ in the animal for which the prognosis is being run is determined using the following equation (Eq. 2).

$$
\frac{\mathrm{dC}_{\mathrm{r}, \mathrm{a}}}{\mathrm{dt}}=\sum_{\mathrm{i}=1}^{\mathrm{i}=\mathrm{n}}\left(\mathrm{x}_{\mathrm{i}} \cdot \mathrm{AE}_{\mathrm{r}, \mathrm{i}} \cdot \mathrm{FMI} / \mathrm{M} \cdot \mathrm{C}_{\mathrm{r}, \mathrm{i}}\right)-\mathrm{C}_{\mathrm{r}, \mathrm{a}} \cdot \lambda_{\mathrm{r}, \mathrm{a}}
$$




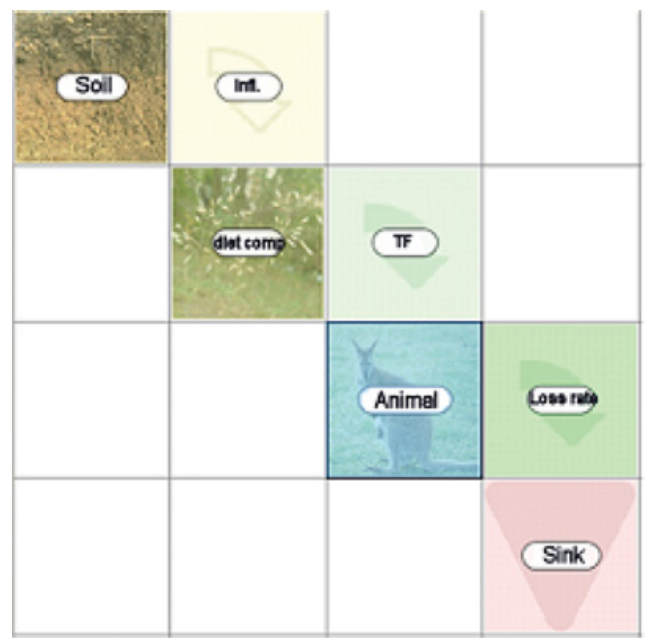

Figure 1. FASTer (lite) model : as used in the present study.

Where:

$\mathrm{x}_{\mathrm{i}}$ is the fraction of the diet associated with dietary component " $\mathrm{i}$ ";

$\mathrm{AE}_{\mathrm{r}, \mathrm{i}}$ is the assimilation efficiency(dimensionless) for radionuclide " $\mathrm{r}$ " within dietary component "i"; $\mathrm{FMI} / \mathrm{M}$ is the ingestion rate per unit mass of animal ( $\mathrm{kg}$ f.w. day ${ }^{-1}$ per $\mathrm{kg}$ f.w.);

$\mathrm{C}_{\mathrm{r}, \mathrm{i}}$ is the activity concentration of radionuclide " $\mathrm{r}$ " in dietary component " $\mathrm{i}$ " $\left(\mathrm{Bq} \mathrm{kg}^{-1} \mathrm{f} . \mathrm{w}.\right)$;

$\mathrm{C}_{\mathrm{r}, \mathrm{a}}$ is the "whole-body" activity concentration of radionuclide " $\mathrm{r}$ " in the animal ( $\left.\mathrm{Bq} \mathrm{kg}^{-1} \mathrm{f.w}.\right)$; and

$\lambda_{\mathrm{r}, \mathrm{a}}$ is the effective loss rate of radionuclide " $\mathrm{r}$ " from animal $\left(\mathrm{day}^{-1}\right)$ incorporating both excretion rate and physical decay of the radionuclide.

Most recently, the FASTer-lite model has been applied in relation to a site contaminated with low level radioactive waste at the Little Forest Burial Ground in Australia [3] within the IAEA's EMRAS II programme. In the process of applying the model for this case, a number of limitations were identified that concerned the trans-generational transfer of radionuclides reflecting the fact that the model does not adequately account for transfer to early life stages or account for the growth of organisms at juvenile stages of the life cycle. The objective of this work was therefore to address these deficiencies with further model developmental work.

\section{METHODOLOGY}

A decision was made to focus on the bird species raven as this formed part of the Little Forest Burial Ground simulation exercise, data had therefore been collated on this animal previously and the transfer to the egg was considered to be an amenable subject for further consideration. $\mathrm{Cs}-137$ and ${ }^{90} \mathrm{Sr}$ were also selected as radionuclides for which suitable data were likely to be available.

The starting point for the model development, therefore, was selected as an adult raven that flies into and resides within a uniformly contaminated area making the assumption that activity concentrations in the environment remain at constant levels with time. The initial parameters required to run the simulation are given below (Table 1).

A more detailed look at life history traits allows us to refine the model making it more specific to the given example. A single (fully grown) bird is followed until the first breeding season. The FASTer-lite model is therefore applied in its original form up to the time for $1^{\text {st }}$ laying of eggs. This has been taken to be 2 years or 730 days (based on information for Corvidae from the website 
Table 1. Parameters for initial model runs of FASTer-lite.

\begin{tabular}{|c|c|c|}
\hline Parameter & Value & References and Comment \\
\hline $\begin{array}{l}\mathrm{x}_{\mathrm{i}} \text {, fraction of the diet } \\
\text { associated with dietary } \\
\text { component "i" }\end{array}$ & $\begin{array}{c}0.24=\text { Grasses and herbs; } \\
0.42=\text { Detrivorous invertebrate } \\
0.34=\text { Carrion (dead wallaby) }\end{array}$ & $\begin{array}{c}\text { CR data from [4] as used } \\
\text { in the ERICA Tool [5]. } \\
\text { Carrion value derived from [3]. }\end{array}$ \\
\hline $\begin{array}{c}\mathrm{AE}_{\mathrm{r}, \mathrm{i}} \text { assimilation efficiency } \\
\text { (dimensionless) for radionuclide } \\
\text { " } \mathrm{r} \text { " within dietary component " } \mathrm{i} \text { " }\end{array}$ & $\begin{array}{l}0.3 \text { for }{ }^{90} \mathrm{Sr} \\
1 \text { for }{ }^{137} \mathrm{Cs}\end{array}$ & Faster modell $[1]$ \\
\hline $\begin{array}{l}\text { FMI, Fresh matter } \\
\text { ingestion rate }\end{array}$ & FMI $(\mathrm{g} / \mathrm{d})=2.065 \mathrm{M}(\mathrm{g})^{0.689}$ & $\begin{array}{l}\text { Allometric for } \\
\text { all birds [6]. }\end{array}$ \\
\hline $\begin{array}{l}\lambda_{\mathrm{r}, \mathrm{a}} \text { the } \\
\text { effective loss rate of } \\
\text { radionuclide " } \mathrm{r} \text { " from } \\
\text { animal a }\end{array}$ & $\begin{array}{c}\lambda=\frac{\ln 2}{645 M^{0.26}} \text { For }{ }^{90} \mathrm{Sr}\left(\mathrm{d}^{-1}\right) \\
\lambda=\frac{\ln 2}{18.36 M^{0.24}} \text { For }{ }^{137} \mathrm{Cs}\left(\mathrm{d}^{-1}\right)\end{array}$ & $\begin{array}{l}\text { Allomterically derived } \\
\text { depuration rates from [1], } \\
\text { where } \mathrm{M} \text { the mass of the } \\
\text { animal is expressed in } \mathrm{kg} \text {. }\end{array}$ \\
\hline
\end{tabular}

http://www.wildbirds.com). The next stage of the process was to simulate the activity from the moment of initial egg formation and laying through to hatching.

There are limited data on transfer of radionuclides to egg although some information has been reported by [7] and [8] for poultry. The data in these publications are presented as transfer coefficients from feed to muscle or to egg contents $\left(\mathrm{F}_{\mathrm{f}}\right)$ in units of $\mathrm{d} \mathrm{kg}^{-1}$ and defined as the ratio of the radionuclide activity concentration in muscle or egg (on a fresh weight basis) divided by the daily intake of the radionuclide at equilibrium. Based on IAEA [8] egg and poultry data, for Sr-90 content is 17.5 times that of the adult. For Cs-137, the egg content is 0.15 times that of the adult.

Once the eggs are laid, there is assumed to be no further input or loss of contamination. For the crow, the incubation time of the eggs has been taken to equal 20 days again based on internet sources (http://www.wildbirds. com give an incubation period of 16-18 days)

Once hatched the dynamic model is implemented. We need to then apply a term for the growth component (Eq. 3), e.g.

$$
\frac{\mathrm{dC}_{\mathrm{r}, \mathrm{a}}}{\mathrm{dt}}=\sum_{\mathrm{i}} \mathrm{x}_{\mathrm{i}} \cdot \mathrm{AE}_{\mathrm{r}, \mathrm{i}} \cdot \mathrm{FMI} / \mathrm{M} \cdot \mathrm{C}_{\mathrm{r}, \mathrm{i}}-\mathrm{C}_{\mathrm{r}, \mathrm{a}} \cdot\left(\lambda_{\mathrm{r}, \mathrm{a}}+\mathrm{g}_{\mathrm{a}}\right)
$$

Here " $\mathrm{g}_{a}$ " is the relative growth rate $\left(\mathrm{d}^{-1}\right)$. Other terms are described in Eq. (2)

Growth curves for birds (and other animals) are often sigmoidal in form [9] and logistic functions have been used specifically to describe the growth of species from the Corvidae family [10] and to model changes in activity concentrations of selected radionuclides with time for fish, accounting for growth rates in aquatic systems [11].

Considering the fact that birds do not grow infinitely, it can be assumed that the raven's relative growth rate eventually converges to zero as it reaches the adult stage. By that time it has acquired a steady state mass $M_{\mathrm{ss}}$ (e.g. of adult raven $=0.6 \mathrm{~kg}$ ). The difference between $\mathrm{M}_{\mathrm{ss}}$ and $\mathrm{M}$ indicates the potential capacity for its growth. These can be formulated mathematically by assuming that the relative growth rate is proportional to the potential capacity for the growth:

$$
\mathrm{dM} / \mathrm{dt}=\mathrm{aM}\left(\mathrm{M}_{\mathrm{ss}}-\mathrm{M}\right)
$$

This is a simple logistic growth model, where a is a positive constant. The general solution of this differential equation has the following form:

$$
\mathrm{M}(\mathrm{t})=\frac{\mathrm{M}_{\mathrm{ss}}}{1+\mathrm{be}^{-\mathrm{aM}_{\mathrm{ss}} \mathrm{t}}}
$$




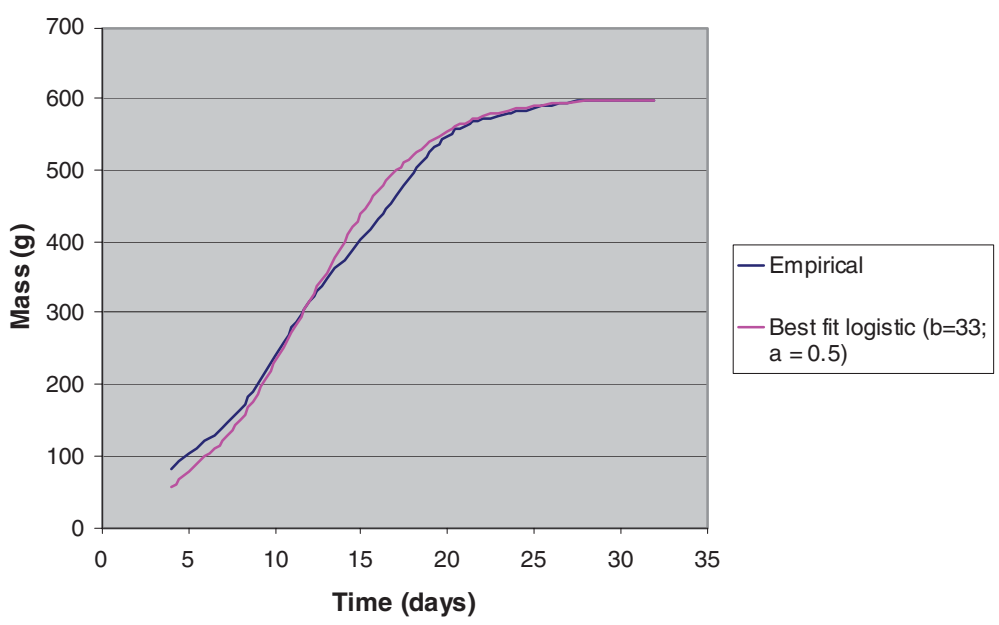

Figure 2. Growth curves for crows showing the correspondence between empirical data (based on [10]) and a least squares fitted logistic model (Eq. (4)).

Here $\mathrm{b}$ is a constant. For the case under consideration this equation expresses the mass growth of the raven chick. Now by making use of the last two equations we are able to find an expression for the last term in Equation (3):

$$
\mathrm{g}_{\mathrm{a}}(\mathrm{t})=\mathrm{aM}_{\mathrm{ss}}\left[1-\frac{1}{\left(1+\mathrm{be}^{-\mathrm{aM}_{\mathrm{ss}} \mathrm{t}}\right)}\right]
$$

Empirical data for the growth (in terms of mass) of carrion crow (Corvus corone corone) chicks have been used as a suitable related species.

The value of ' $a$ ' has been taken to be 0.5 , a value which falls approximately in the middle of the bounds derived by [10] based on bird groups from urban and agricultural areas and separated according to sex. Using this value of 0.5 , a least squares regression can be applied to derive a value of $b=33$. Furthermore, the Ingestion rate term now also becomes time dependent for the developing chick as dose the depuration rate. For example, using the allometric relationship for all birds, the fresh matter ingestion rate, FMI $(\mathrm{g} / \mathrm{d})=2.065 \mathrm{M}(\mathrm{g})^{0.689}[6]$, becomes mass and therefore time dependent.

\section{RESULTS}

Results from model runs are presented for ${ }^{90} \mathrm{Sr}$ in Figure 3 and for ${ }^{137} \mathrm{Cs}$ in Figure 4.

The model simulates the peak in activity in the egg associated with the much higher transfer of ${ }^{90} \mathrm{Sr}$ to this early life stage compared to the adult. However, the relative activity concentrations are seen to fall rapidly following hatching and initial growth of the chick and within a few 10s of days, the chick concentrations actually fall substantially below that of the adult.

With regards to ${ }^{137} \mathrm{Cs}$, there is a substantial drop in activity in the egg compared to the adult but the growing chick quickly attains a similar activity concentration to the adult bird with constant levels being obtained within a period of 100 days or so. This undoubtedly reflects the facts that biological half-lives of radiocaesium in small animals tend to be short (days to tens of days). 


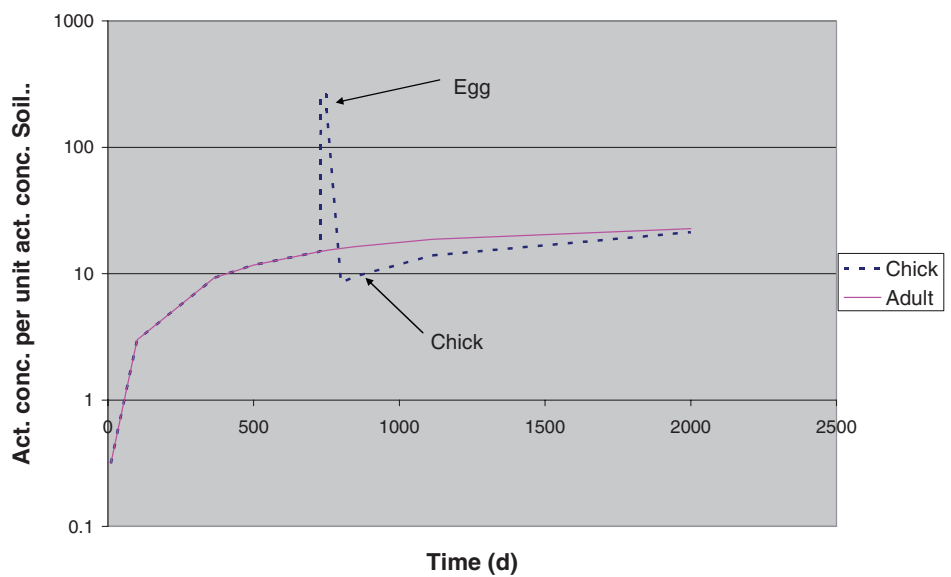

Figure 3. Activity concentrations relative to unit activity concentrations in soil for ${ }^{90} \mathrm{Sr}$ in adult raven (Eq. (2)) and chick (Eq. (3) \& (6)) with eggs laid at $\mathrm{t}=730$ days.

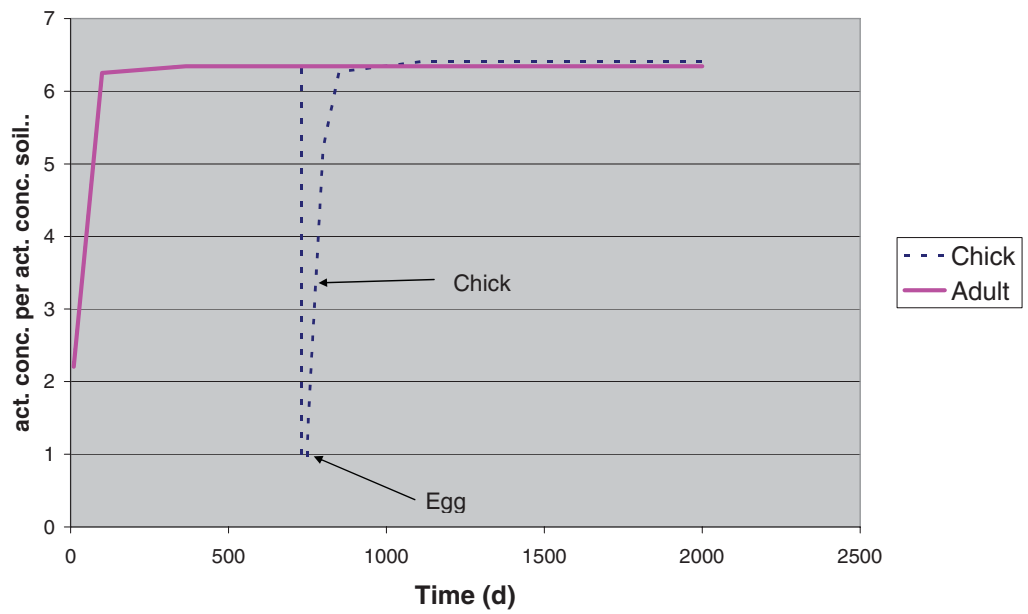

Figure 4. Activity concentrations relative to unit activity concentrations in soil for ${ }^{137} \mathrm{Cs}$ in adult raven (Eq. (2)) and chick (Eq. (3) \& (6)) with eggs laid at $\mathrm{t}=730$ days.

\section{Acknowledgments}

This work was performed within the STAR (A Strategy for Allied Radioecology) Network of Excellence supported by the EC-EURATOM $7^{\text {th }}$ Framework Programme and Norwegian Research Council. The financial support of the Norwegian Research Council is gratefully acknowledged.

\section{References}

[1] Brown, J.E., Strand, P., Hosseini, A. \& Børretzen, P. (Eds.). Handbook for assessment of the exposure of biota to ionising radiation from radionuclides in the environment. Deliverable Report for the EC Project FASSET-Contract No. FIGE-CT-2000-00102, (Norwegian Radiation Protection Authority, Østerås, Norway, 2003), pp.101. 
[2] Beresford, N.A., Barnett, C.L., Brown J.E., Cheng, J-J, Copplestone, D., Gaschak, S., Hosseini, A., Howard, B.J., Kamboj, S., Nedveckaite, T., Olyslaegers, G., Smith, J.T., Vives i Batlle, J., Vives-Lynch, S. and Yu, C., J. Radiol. Prot. 30 (2010) 341-373.

[3] Johansen, $M$ et al., Dose modelling comparison for terrestrial biota; IAEA EMRAS II Biota Working Group's Little Forest Burial Ground Scenario. ICRER Conference Canada (in prep).

[4] Beresford, N.A., Barnett, C.L., Howard, B.J., Scott, W.A., Brown, J.E., Copplestone, D., J. Env. Rad. 99 (2008) 1393-1407.

[5] Brown, J. E., Alfonso, B., Avila, R., Beresford, N. A.,Copplestone, D., Pröhl, G. Ulanovsky A., J. Env. Rad. 99 (2008) 1371-1383.

[6] Nagy. K.A., Nutr. Abs. Rev. Series B. 71 (2001) 21-31.

[7] Fesenko, S., Howard, B.J., Isamov, N., Beresford, N.A., Barnett, C.L., Sanzharova, N., Voigt G., J. Env. Rad. 100 (2009) 815-822.

[8] IAEA, Handbook of Parameter Values for the Prediction of Radionuclide Transfer in Terrestrial and Freshwater Environments. IAEA Technical Report Series No. 472. (IAEA, Vienna, 2010).

[9] Ricklefs, R. E., Ibis 110 (1968) 419-451.

[10] Richner, H., Journal of Animal Ecology 58, No. 2 (1989) 427-440.

[11] Kryshev A.I., J. Env. Rad. 64 (2003) 67-84. 